\title{
UNA FORMA CALCULADA DE HERIR LA MEMORIA HISTÓRICA REPERCUSIÓN EN TWITTER DE LAS DECLARACIONES DE LOS DIPUTADOS DEL PARTIDO POPULAR PABLO CASADO $Y$ RAFAEL HERNANDO
}

\author{
A way calculated to offend the Historic Memory. \\ Impact on Twitter of the statements of the deputies of the Partido Popular, \\ Pablo Casado and Rafael Hernando
}

\author{
Pedro Paniagua \\ Universidad Complutense de Madrid \\ ppaniagu@ccinf.ucm.es
}

\section{Cómo citar este artículo/Citation:}

Pedro PANIAGUA (2018), "Una forma calculada de herir la Memoria Histórica. Repercusión en Twitter de las declaraciones de los diputados del Partido Popular Pablo Casado y Rafael Hernando", Hispania Nova, 16, págs. 394-416 DOI: https://doi.org/10.20318/hn.2018.4042
Copyright: () HISPANIA NOVA es una revista debidamente registrada, con ISSN II38-7319 y Depósito Legal M 9472-1998. Los textos publicados en esta revista están -si no se indica lo contrario- bajo una licencia Reconocimiento-Sin obras derivadas 3.0 España de Creative Commons. Puede copiarlos, distribuirlos y comunicarlos públicamente siempre que cite su autor y la revista y la institución que los publica y no haga con ellos obras derivadas. La licencia completa se puede consultar en: http://creativecommons.org/licenses/by-nd/3.0/es/deed.es
Resumen: Las declaraciones efectuadas en los últimos años por los diputados del Partido Popular Pablo Casado y Rafael Hernando tratando de menospreciar, cuando no de insultar, a las víctimas del franquismo, han levantado ampollas en la red social Twitter. En el presente artículo vamos a tratar de estudiar estas declaraciones, sobre todo las vertidas en las redes a través de los medios de comunicación y las correspondientes reacciones que han suscitado entre los usuarios de esta red social. El tratamiento va a ser eminentemente periodístico y pretende abarcar dos grandes campos. El primero partiría del supuesto de que las afirmaciones de los diputados pudieran considerarse opinión, por lo que trataríamos de confirmar tal hipótesis mediante la comprobación de los enunciados propios de este tipo de periodismo y su relación con otro campo limítrofe como es la manipulación. En el segundo campo de análisis trataríamos de delimitar las palabras de los dos políticos de acuerdo a las reglas de la información e interpretación periodísticas con el objetivo de comprobar si la información contenida en ellas se ajusta a la realidad, y de si la posible interpretación se efectúa utilizando unos criterios de actuación objetivos, o por el contrario no se respeta ninguno de los pasos lógicos que deben guiar todo proceso interpretativo periodístico que pretenda ajustarse a unos mínimos estándares éticos. Naturalmente, la opinión es libre, y desde este punto de vista, y descendiendo a los casos concretos, es perfectamente legítimo manifestar que las víctimas no merecen ninguna subvención. Otra cosa es verter afirmaciones enmascaradas bajo esa supuesta libertad de opinión. Por ejemplo diciendo que los descendientes de las víctimas solo se han movido cuando ha habido subvenciones.

Palabras clave: Partido Popular, Pablo Casado, Rafael Hernando, Twitter. 
Abstract: The statements made in recent years by deputies of the Popular Party Pablo Casado and Rafael Hernando trying to belittle, if not insult, the victims of Francoism, have raised blisters on the social network Twitter. In the present article, we will try to study these statements, especially those expressed in the networks through the media and the corresponding reactions that have aroused among the users of this social network. The treatment will be eminently journalistic and aims to cover two large fields. The first one assumes that the statements of the deputies could be considered opinion, so we try to confirm this hypothesis by checking the statements of this type of journalism and its relationship with a boundary field such as manipulation. In the second field of analysis we would try to delimit the words of the two politicians according to the rules of journalistic information and interpretation in order to verify if the information contained in them is true and if the possible interpretation is It does so using objective criteria of performance, or on the contrary, it does not respect any of the logical steps that should guide any journalistic interpretive process that tries to conform to some minimum ethical standards. Naturally, opinion is free, and from this point of view, and descending to concrete cases, it is perfectly legitimate to state that the victims do not deserve any subsidy. It is another thing to shed masked claims under that supposed freedom of opinion. For example, the descendants of the victims have only moved when there have been subsidies

Keywords: Partido Popular, Pablo Casado, Rafael Hernando, Twitter. 


\section{Introducción*}

En el primer resumen del artículo, mandado como comunicación a la organización del congreso que se cita en nota al pie en la portada el 11 de enero de este año, nos proponíamos como periodo temporal de estudio la última legislatura. Normalmente suele comprender este periodo cuatro años aproximadamente, si bien en este caso, debido a las dificultades para formar gobierno derivadas de los últimos resultados electorales, el lapso de tiempo varió pues ahora mismo nos hallamos en la XII legislatura, que empezó el 19 de julio de 2016; la anterior, la XI, se extendió entre el 13 de enero de 2016 y el 5 de marzo del mismo año; y la $X$ tuvo lugar entre el 13 de diciembre de 2011 y el 27 de octubre de 2015. Ese 13 de diciembre de 2011 es cuando empezó el actual mandato de Mariano Rajoy. Para tratar de las declaraciones de los diputados del Partido Popular (PP) Pablo Casado y Rafael Hernando sobre la memorias histórica, por tanto, nos tendremos que remontar un mínimo de dos legislaturas. Pero además, como las primeras declaraciones que nos interesan fueron hechas en 2008, durante el gobierno de José Luis Rodríguez Zapatero, habremos de remontarnos todavía una legislatura más para poder arrancar nuestro estudio. La cuestión no implicaría mayor problema que una mera precisión temporal, si no fuera porque ese mayor número de legislaturas hacen que nuestro país esté en una época más convulsa desde el punto de vista político, con un gobierno que ha pasado de estar en manos del Partido Socialista Obrero Español (PSOE) en la IX legislatura, a las del

\footnotetext{
* Una primera versión de este artículo se presentó como comunicación en el Congreso Internacional LA ESPAÑA ACTUAL: CUARENTA AÑOS DE HISTORIA (1976-2016), Cádiz, 10-12 de mayo de 2017, Mesa Temática E48: Las Plataformas Sociales en línea para la recuperación de la Memoria Histórica en la España Actual.

Este artículo es uno de los resultados del Proyecto HISMEDI: "Historia y Memoria Histórica online. Retos y oportunidades para el conocimiento del pasado en Internet", financiado por el Ministerio de Economía y Competitividad y el Fondo Europeo de Desarrollo Regional (FEDER) con referencia HAR2015-63582-P MINECO/FEDER.
} 
PP con mayoría absoluta en la $\mathrm{X}$, a un gobierno en funciones en la $\mathrm{XI}$ y por último a otro del PP sin mayoría absoluta en la actual.

De todas formas, para lo sustancial de este trabajo -es decir, para estudiar cómo las citadas declaraciones han herido la memoria de las víctimas del franquismo-, tal variedad de gobiernos solo pone de manifiesto que la línea del PP sobre este tema es única e invariable y no depende en absoluto de qué partido gobierne o en qué condiciones. El menosprecio de los populares hacia los perdedores de la Guerra Civil ha sido una constante, sin duda alguna en los últimos nueve años analizados, pero también, a poco que recordemos, durante los treinta anteriores de democracia, lo cual nos lleva establecer una primera línea provisional en la que no se ha producido cambio alguno al respecto entre la posición de este partido desde su creación en 1976 hasta la actualidad. La línea, además, se remonta mucho más atrás, pongamos otros cuarenta años, pues, en lo esencial, el partido del gobierno actual no muestra sobre este tema diferencias significativas con lo defendido por el franquismo desde sus orígenes.

Quizá, antes de entrar de lleno en el trabajo, no esté de más recordar que la forma dominante de restitución de la memoria en nuestros días consiste en la difusión de hechos silenciados en su momento por el franquismo, y que las declaraciones que nos proponemos analizar condicionan en cierta forma la correcta difusión de esos hechos. No creemos que sea necesario insistir ahora sobre el carácter represivo del bando vencedor de la guerra civil y el silencio al que llevó esa represión sobre el bando perdedor. Baste señalar, a modo de ejemplo, los trabajos del propio Aróstegui (2006), y de otros autores como Aguilar (2006), Navarro (2002), Núñez (2004) y Reig (2009).

\section{Metodología e hipótesis.}

Para analizar nuestro objeto de estudio, examinaremos en primer lugar las declaraciones más significativas de los dos diputados elegidos. Su elección se debe a que ambos pueden considerarse representativos de la postura más beligerante de su partido respecto a la Memoria Histórica. Además, ambos han desempeñado, o desempeñan, cargos de importancia en lo que se refiere a la comunicación institucional del PP, por lo que sus palabras pueden considerarse sin ambages como la opinión del 
partido. Ninguno, por otro lado, ha sido desmentido ni matizado en estas declaraciones por el presidente ni por otro cargo institucional relevante del gobierno ni del partido. El carácter significativo de sus palabras, por otra parte, viene dado por su permanencia en el tiempo en la memoria colectiva reciente de los afectados, y por su capacidad para herir esa otra memoria más amplia que denominamos histórica.

Desde un punto de vista material, el análisis de las declaraciones se llevará a cabo tomando como base la prensa más cercana al momento de expresarlas. También, documentos audiovisuales contrastados que nos permitan una transcripción exacta de las palabras para poderlas oponer a los intentos de rectificación de los dos políticos. El análisis de lo audiovisual nos permite además analizar el contexto en el que se han producido las declaraciones, y las reacciones que in situ han provocado.

De ahí estudiaremos su traslado a la red social Twitter y las reacciones que en ella se han producido teniendo en cuenta los siguientes criterios: En primer lugar, para cada uno de los dos diputados, y con el fin de no introducir desde el principio ningún tipo de sesgo político que pudiera viciar la investigación, utilizaremos como primer criterio de búsqueda los hashtags con los nombres propios de ambos. En segundo lugar intentaremos acceder cronológicamente hasta el momento exacto de cada declaración para ver cómo se ha producido la publicación y las posibles reacciones que haya habido en ese mismo momento. A continuación estudiaremos la repercusión en días posteriores de acuerdo a un criterio de operatividad en función del número de tuits que haya en cada caso. Por último, recorreremos los distintos criterios de búsqueda que nos ofrece la red social para cada etiqueta, con el fin de analizar distintos momentos en los que los tuits estudiados hayan podido tener respuesta. Estos criterios son: "Destacados", "Recientes", "Fotos", "Vídeos", "Noticias" y "Transmisiones". Para la consistencia del relato, y cuando sean pertinentes, de cada tuit se podrán consignar datos relativos al autor, hora, fecha, hashtags asociados, número de respuestas, de retweets, de "me gusta", de seguidores del autor, etc...

Todo lo anterior, que solo superficialmente obedecerá a un criterio cuantitativo, se atendrá más bien a uno cronológico y de notoriedad, y se verá potenciado por un análisis cualitativo esencialmente periodístico. Será preciso aplicar una cualidad o exigencia que señala Pons referida al historiador (2013, p. 195): “Introducir orden en el 
caos". Cada declaración de los políticos se verá sometida a criterios éticos y prácticos de redacción que nos ayuden a deslindar cada juicio, interpretación e información y a situar cada uno en su lugar con el fin de alcanzar resultados que midan parámetros de veracidad, legitimidad, y sustentabilidad. Los resultados de los análisis efectuados con estos criterios se verán apoyados en ocasiones por mensajes de la red social. Naturalmente, a dos políticos no se les pueden exigir normas éticas del periodismo, pero sí se pueden estudiar sus declaraciones con estándares periodísticos y ver en qué puntos esas declaraciones son lícitas o legítimas desde un punto de vista comunicativo o bien devienen en facetas indeseables de la comunicación como la manipulación, o la desinformación. En ese caso, serían igual de condenables que si provinieran de un periodista.

La utilización de Twitter para la difusión de mensajes políticos ha sido estudiada recientemente con profusión. Baste señalar algunos de los primeros casos como el de Small en 2011, que destacaba el rasgo informativo y difusor de la red social al analizar las elecciones canadienses de aquellos años. Junto a este, otros casos del uso de la red en la configuración de la opinión pública se refieren al de México en 2009, donde una protesta masiva en Twitter contra la imposición de un nuevo impuesto desembocó en una audiencia formal en el Senado de la República, en el que está considerado como "el primer uso conocido públicamente de Twitter para un acto político social en el cual se convoca a una masa urbana en un sentido reivindicativo" (Rihawi, 2017, p. 80).

La línea política del PP con respecto a la Memoria Histórica no ha variado desde los orígenes del franquismo hasta hoy. El periodo que abarca esta línea es muy amplio, nada menos que ochenta años, y excede el plazo estudiado por este trabajo, por lo que no se va a demostrar. Sin embargo, la pervivencia del franquismo ha sido puesta de manifiesto desde el lado de la historiografía, como por ejemplo Navarro (2002, p 201): "En la España que yo conozco hay miles (¿millones?) de españoles que reivindican el régimen franquista". Otra hipótesis ya ha sido adelantada en el titular de este trabajo, y se puede volver a expresar en los siguientes términos: Las declaraciones de los diputados del Partido Popular Pablo Casado y Rafael Hernando constituyen formas sui generis de herir la Memoria Histórica instaladas en la vertiente comunicativa de la política de su partido. 


\section{Análisis}

\subsection{Declaraciones de Pablo Casado}

El 20 de septiembre de 2008, en un mitin de su partido en Madrid, Pablo Casado declaró: "Yo estoy convencido de que la inmensa mayoría de jóvenes son del PP pero aún no lo saben. ¡Si es que en pleno siglo XXI no puede estar de moda ser de izquierdas, pero si son unos carcas! Están todo el día con la guerra del abuelo, con las fosas de no sé quién, con la Memoria Histórica". (El Periódico, 19.6.2015).

La declaración, como muy bien subrayó una twittera ${ }^{1}$ cuatro años después, permaneció "en el recuerdo de todos" y "no dejó indiferente a nadie". En estas dos breves afirmaciones hallamos dos de las características de las declaraciones de Casado que, como ya hemos avanzado, las van a hacer significativas. Por un lado su permanencia en el tiempo. El político las hizo en 2008, el recuerdo de esta usuaria de Twitter se produce en 2012, y todavía en 2017 vamos a encontrar referencias a esas palabras. Por otro lado, efectivamente, no dejaron indiferente a nadie. De los 46 tuits encontrados en la red social con los criterios señalados en la metodología, e introduciendo en ocasiones la fecha de 2008 para concretar más la búsqueda, un total de 44 son contrarios a Casado. Si del conjunto de usuarios de Twitter se desprende algún tipo de sesgo político es algo que desconocemos y que en nada en turbia la imparcialidad de la investigación, pues, como ha quedado expresado, los criterios de búsqueda han sido empleados con el mayor de los escrúpulos en aras de obtener unos resultados valiosos desde el punto de vista de la neutralidad informativa.

Naturalmente, como suele suceder en estos casos, Casado respondió en los medios (Ibid.) que sus palabras se habían "sacado de contexto", que su discurso entero "duró 15 minutos y no 15 segundos" y que su deseo era "respetar a todos".

\footnotetext{
${ }^{1}$ El que una usuaria de la red social sin cualificación alguna, o de la que no conocemos cualificación alguna, o que no hace valer cualificación alguna en la referida comunicación, nos dé las claves de interpretación de estas declaraciones forma parte de la esencia de Twitter. Según mantuvimos en otro foro (Sanmartí, Paniagua y de Ramón, 2002:444), el gran cambio de los medios digitales radica "en la posibilidad de que la información -que utiliza el periodista como mañana utilizará el historiador- esté al alcance de usuarios sin cualificar que, además, como ocurre en cualquier proceso de plebeyización, están orgullosos de esa falta de cualificación".
} 
Pero, como también suele suceder, esa respuesta solo recoge excusas de mal perdedor, pues nada se sacó de contexto, como perfectamente recoge el vídeo de su intervención (vid. epígrafe 6 "Referencias hemerográficas y enlaces), donde se puede apreciar de forma diáfana que sus palabras no iban precedidas ni seguidas de otras que cambiaran o matizaran el sentido de las reproducidas. El resto del discurso hacía alusión, en lo que nos toca, a otras cuestiones, como que su abuelo fue víctima del franquismo, o que la Ley de Memoria Histórica de Rodríguez Zapatero le parecía que abría heridas. En nada alteran tampoco estas cuestiones el sentido de las declaraciones analizadas. Sí, en cambio, añaden una dosis considerable de cinismo otras palabras pertenecientes a la respuesta del diputado en las que manifiesta que su intención con el citado discurso era "respetar a todos". Nada más alejado del respeto que las palabras citadas, que además cobran mayor gravedad al escuchar y ver en el vídeo el tono de mofa absoluto con el que las dijo.

Desde un punto de vista periodístico, las tres excusas de Casado se pueden considerar, por este orden: Falsedad, en el caso de que sus palabras se han sacado de contexto. Falacia, en la frase que dice que su discurso duró 15 minutos y no 15 segundos, pues si bien puede ser cierta no aporta nada relevante al debate, puesto que el discurso entero fue de menosprecio a las víctimas. Lo de "respetar a todos" vuelve a ser falsedad, según ha quedado explicado más arriba. Ninguna de las tres afirmaciones es una opinión. Las tres son información, o desinformación, más bien; pues dos de ellas, como ha quedado dicho son falsedades y la otra es una información cierta pero irrelevante, declarada solo con el fin de intoxicar.

La indignación en Twitter no paró en ese año de 2012, primero encontrado con los criterios de búsqueda señalados, ni en los sucesivos. En enero/febrero de 2015 encontramos una batería de 7 tuits, todos coincidentes en mostrar una posición de repulsa hacia las declaraciones del diputado popular. El 13 de enero un usuario de la red pregunta "¿Las fosas de no sé qué? ¿Eso es manera de dirigirse a la gente? Eso es no tener vergüenza”. El desvergüenza a la que alude se basa en que en esa fosa (recordémoslo, aunque sea obvio) hay un familiar muerto por un ejército golpista, es decir ilegal, y ni siquiera dejan que sus familiares lo entierren dignamente. Llamar a esos familiares "carcas" o hablar en tono de burla de "la tumba del abuelo" es una 
ofensa clara que contrasta con el respeto que el PP exige para las víctimas del terrorismo, como veremos posteriormente en algún otro mensaje de Twitter. Además, el fondo de la argumentación de Casado también se puede considerar como falacia, es decir, una tesis sin lógica, sin adecuación entre el punto de partida y el resultado, y sin fortaleza en su esquema intelectual. El político popular viene a decir que quienes defienden la memoria histórica son condenables porque de la Guerra Civil hace ya mucho tiempo. Pero la Guerra interesa no solo a los afectados. "El pasado está entre nosotros y se resiste a marcharse porque la sociedad así lo demanda", dice Eiroa (2014:359). $Y$ es cierto, no es solo una cuestión de dignidad personal o familiar, sino que es algo que ya forma parte de buena parte de la sociedad.

El 14 de enero de 2015 una twittera sarcástica señala: "Decía Pablo casado en 2008 que la mayoría de los jóvenes eran del PP y no lo sabían. He llegado a esta conclusión: NO soy del PP y lo sé”. Otro, por las mismas fechas, ponía el dedo en la llaga al afirmar: "La consigna del PP a Pablo Casado es crispar al máximo la vida política de \#Españistán. Ya lo hicieron en 2008 con el terrorismo y la cagaron”. Un tercero incurre directamente en la descalificación personal: "El discurso que dio Pablo Casado en 2008 es una burla a víctimas y ciudadanos. Sinvergüenza”. Los insultos suben de tono en otros twitteros: “"En pleno siglo XXI no se puede ser de izquierdas: qué carcas. Que si las batallas del abuelo, que si las fosas...". HDP”. Algunos se preguntan: "¿Qué va a decir el hijo de quienes provocaron la batallas del abuelo y lo enterraron donde no tocaba?" Otros califican el discurso de Casado de "facha" y "faltón".

También, como dijimos, hay algún mensaje a favor del político conservador, aunque son minoría: "Todavía me acuerdo del brillante discurso de Pablo Casado en 2008 en su $2^{\circ}$ Congreso. Y sigue siendo igual de brillante". Pero las aguas del rechazo vuelven en seguida a su cauce, pues el mensaje siguiente no deja lugar a dudas en cuanto a su posicionamiento. Va a citar a un conocido twittero claramente contrario a línea del Partido Popular: "Pablo Casado en 2008 no tiene desperdicio. Esta es la regeneración del PP. Vía @FacuDíazT Muy grande encontrando esto". El último tuit de este bloque, correspondiente a enero de 2015 y buscado mediante la combinación de hashtag y la fecha de 2008, reproduce simplemente las palabras de Casado e 
incluye un enlace al vídeo en You Tube. Este enlace lo incluyen muchos de los mensajes reproducidos.

En enero de 2015 Pablo Casado pasa a ser nombrado portavoz electoral del PP para las elecciones municipales y autonómicas que se iban a celebrar en mayo de ese año. Con ese motivo, el programa televisivo "El Intermedio", de La Sexta, rescata algunos de los mejores momentos de la carrera del joven político. Por supuesto, no pueden faltar sus declaraciones del congreso de 2008. En seguida vamos a ver su repercusión en Twitter, pero antes conviene repasar otro de los momentos de su discurso que el programa televisivo se encarga de recordar. Son unas declaraciones suyas en las que, dentro del hilo argumental de que la izquierda es carca y lo moderno es la derecha, llega a decir: "En el 89, los jóvenes nos pusimos delante de un tanque en Tiananmen parando al comunismo. $Y$ tiramos con nuestras manos el muro de Berlín” (eldiario.es, 14.1.2015). Si bien es cierto que estas palabras están pronunciadas por una persona joven (Casado cuenta en ese momento con 27 años), el uso de la primera persona se nos antoja excesivo, pues en el 89 tenía 8 y, por muy precoz que fuera, obviamente no tenía edad suficiente para ponerse delante de un tanque ni para derrumbar el Muro de Berlín "con sus propias manos". Más allá de ese uso interesado de la primera persona, la falacia encubre un pecado mucho mayor, y es omitir que tanto Tiananmen como la caída del Muro fueron hechos que pasaron a la Historia por luchar precisamente contra una dictadura, exactamente lo mismo que hacían las personas que en España acabaron enterradas en fosas comunes. El tono jovial de la intervención esconde, por tanto, una interpretación de los hechos interesada basada en premisas falsas.

Las palabras de Casado, además, se pueden encuadrar dentro de otros conceptos como "manipulación". Para Burgueño (2008:26-28), el "concepto genérico de manipulación se refiere inicialmente a tratar de manejar las cosas para obtener un resultado concreto alterando su naturaleza". Dice también este autor que "las mejores manipulaciones suelen ser las que entretejen retazos de "verdades" de tal forma que el mensaje que transmita sea algo bien diferente de lo que ocurrió". Repasemos las palabras de Casado: "En el 89, los jóvenes nos pusimos delante de un tanque en Tiananmen parando al comunismo. Y tiramos con nuestras manos el muro de Berlín.” 
Veamos qué hay de verdad y qué de manipulación en estas declaraciones: "En el 89" (verdad), "jóvenes delante de un tanque en Tiananmen parando el comunismo" (verdad), "tirando el muro de Berlín" (verdad). La manipulación radica en el uso obsceno de la primera persona, pues si bien es verdad que el político popular es joven, y que quienes ejecutaron los hechos que se relatan también lo son, eso no da pie a establecer ningún paralelismo entre las dos edades habida cuenta de que han pasado veinte años. Es como si al decir que Homero, antes de morir, se encontró en ĺos a dos jovencitos que parecían pescar pero que en realidad se estaban despiojando (Hesíodo 2010:141), diéramos pie a que se interpretara que uno de esos dos jovencitos, por el hecho de serlo, fuera Pablo Casado. Pero más allá de una identificación personal que, como vemos, conduce al absurdo, el intento del "joven" político popular es atribuirse para su partido unos méritos que en absoluto le corresponden. ¿Tuvo el PP algo que ver en Tiananmen o en la caída del Muro? Obviamente no, pero Casado, por esa falsa vía generacional, lo da a entender. Su razonamiento esconde (poco, porque prácticamente los enuncia así) dos silogismos, no solo basados en premisas falsas, sino, además, de engranajes muy toscos: buscar tumbas de hace ochenta años es de carcas, la izquierda lo hace, luego la izquierda es carca. Luchar contra el comunismo en Tiananmen y por la caída del Muro lo hicieron los jóvenes, nosotros somos jóvenes, luego nosotros (la derecha) fuimos los que luchamos. De premisas retorcidas sin ninguna lógica, solo pueden salir, naturalmente, despropósitos. Pero, en la exaltación de un mitin, con un público entregado, no opera tanto la racionalidad como la visceralidad, por eso esas manipulaciones basadas en premisas falsas y tan poco sutiles pueden llegar a funcionar.

La publicación en Twitter de ese artículo de eldiario.es contó con unos datos de repercusión relevantes: 30 respuestas, 186 retweets y 29 "me gusta". En la mayoría de los casos (todos de "Destacados", pues no se encontró nada en "Personas", "Fotos", "Vídeos" ni "Noticias") los mensajes fueron contrarios a Casado. Por ejemplo: "Lo de que "descansen en paz" cada uno se lo toma como le da la gana, sobre todo si son católicos y del PP”. Este tuit hace referencia a que Casado, al igual que Hernando, como luego veremos, se manifiesta partidario de dejar que los muertos descansen en paz. Otro mensaje dice: "A este la fosa que le pone es la del Valle de los Caídos". Otro 
señala: "Qué forma tan sutil de cagarse en los muertos de la gente". Algunos, no sin razón, prevén el posible conflicto que las declaraciones de Casado pueden ocasionar: "Ahora un torturado por el franquismo le dice me cago en tu...y recibe una denuncia... Me conformaré con llamarle ¡i¡Gilipollas!!!". A otros usuarios las declaraciones les llevan a cuestionarse todo el cambio de imagen que en ese tiempo pretendía ofrecer el partido conservador: “¿Y esta es la nueva imagen del @PPopular??? Qué miedo y qué poco les queda". El humor, claro, tampoco está ausente en esta remesa de mensajes: "Pablo Casado es la demostración palpable que un cuerpo humano puede vivir (y bastante bien, según parece) sin cerebro".

La mayor parte de los mensajes, sin embargo, no recurre al humor, sino más bien a una queja agria en toda regla, como "este chico es una vergüenza, no siente ni padece", o "sí, Pablo, a mí me preocupan las fosas, mis fosas nasales por el hedor a mierda que exhala tu boca cada vez que la abres". Otro recurso habitual es el insulto directo. Los hay de todo tipo: "animalico", inepto, carca, pijo, facha, fascista, tonto, sinvergüenza...

Las respuestas de Casado son en general bastante torpes. Cuando las analizamos haciendo uso de argumentos racionales no se sostienen. Por ejemplo, en el artículo citado de El Periódico de 19.6.2015 negaba que se pudieran equiparar sus declaraciones a los tuits de Guillermo Zapata. Estos se enmarcan dentro del contexto del humor, mientras que sus palabras, aunque dichas en un tono jocoso, no responden a las características del humor profesional, ni su objetivo era hacer reír, sino descalificar a la izquierda mediante el recurso fácil de reírse de sus muertos. Hacer reír y reírse no es lo mismo, ni se parecen.

En el contexto de los argumentos racionales alejados de la respuesta visceral, encontramos un tuit del 2 de noviembre de 2015 que acierta de pleno porque desbarata la tesis central del discurso del diputado del PP: ““'Los carcas son los de izquierdas", decía Pablo Casado en 2008. De un partido que no quiere quitar honores a Franco, qué curioso". Efectivamente, en un plano más amplio, cabe recordar que las palabras del joven político conservador se producen al mismo tiempo que su partido se niega a eliminar cualquier vestigio del franquismo. Pero, además, si a las fosas nos referimos, lo que el PP pretende es no cuestionar un régimen que nació hace 80 años, 
por lo que acusar de carcas a quienes quieren reparar un daño solo puede ser calificado, otra vez, de falacia.

Y si decíamos al principio que las declaraciones de Casado son una forma de herir la memoria, entre otras cosas porque han tenido una clara vigencia en el tiempo, una prueba palpable de que esto es así la tenemos en que han vuelto a ser recordadas hace apenas unas semanas. El 28 de abril de este año, en medio del escándalo de Ignacio González que le llevó a prisión por la Operación Lezo, Gerardo Tecé reproducía en Twitter unas declaraciones del político popular en las que decía: "Cuando Ignacio González y Granados se defendían, parecía verosímil”, a lo que añade el twittero: "Estas batallitas de los abuelos sí le interesaron". El mensaje tuvo 245 retweets y 408 "me gusta", y prueba que cuando se quiere ridiculizar a Casado todavía se usan esas declaraciones hechas hace ahora nueve años.

\subsection{Declaraciones de Rafael Hernando}

El 4 de noviembre de 2013, Rafael Hernando, entonces portavoz adjunto del PP en el Congreso, declara en la tertulia "El Cascabel" de 13 TV que "Ios familiares de las víctimas del franquismo se acuerdan de desenterrar a su padre solo cuando hay subvenciones" (La Voz de Galicia, 26.11.2013). La afirmación le vale una denuncia por parte de la Asociación para la Recuperación de la Memoria Histórica por un supuesto delito de injurias graves. Él, como vimos que ocurrió con Pablo Casado, y como suele suceder siempre en este tipo de casos, niega que haya hecho esas declaraciones y afirma que el entrecomillado es falso. Viendo el vídeo (El Periódico, 26.11.2013) se aprecia que textualmente lo que dice es: "Algunos se han acordado de su padre, parece ser, cuando había subvenciones para encontrarlo". Si bien la transcripción de La Voz de Galicia no es literal, el sentido es claro, y no se trata de una interpretación periodística ya que de las muchas vías por las que puede circular la interpretación síntesis, complicidad, explicación... (Paniagua, 2017)- ninguna se da en este caso. Simplemente el periódico ha atribuido el sujeto claro al que se refiere el "algunos" para que el titular tenga sentido. En modo alguno supone esto interpretación alguna por parte del periódico, sino una pura y simple licencia gramatical que hace que el epígrafe sea comprensible por el lector. Que el sentido no cambia es algo que fácilmente se 
puede colegir también del vídeo. Hernando, precisamente, se escudará más tarde en que él dijo "algunos" y no "todos", pero la excusa vuelve a estar, como en el caso de Pablo Casado, fuera de lugar porque habla de las víctimas del franquismo y nadie, en una construcción normal de una frase dice "todas las víctimas del franquismo". Si se dice luego "algunos", con el tono de prepotencia y de burla que se puede apreciar en las imágenes, está claro que se pretende hacer una generalización (vid. Enlace en epígrafe 6).

Pero, con todo, con ser graves esas declaraciones, atenta más contra la lógica de cualquier discurso un preámbulo que las precede en el que Hernando se refiere a Europa. En un tono socarrón y ampuloso, como en él suele ser habitual, tono que, por otra parte, define su catadura moral, exclama dirigiéndose al presentador de El Cascabel, Antonio Jiménez: "Imagínese usted, don Antonio, que en Europa, que ha habido cien millones de muertos en la II Guerra Mundial, cada gobierno le pidiera al gobierno de al lado que levantara las cunetas, las carreteras para encontrar los muertos de sus soldados (sic.)". Pero además de la torpeza ética, está la torpeza intelectual de un argumento tan endeble. Como muy bien se encargaron de recordar dos usuarios de Twitter, al hilo de un programa sobre el aniversario del bombardeo de Guernica que emitió La Sexta el 28 de abril, "Alemania pidió perdón” y "En Alemania los descendientes de los genocidas reniegan de ellos". Lo curioso es que el primero de estos dos tuits no iba dirigido a Rafael Hernando, sino a Pablo Casado y lo dicho iba precedido de la siguiente frase: "Hola @pablocasado has visto \#L6cGernica?... no creo, seguro que te parece cosa de carcas y batallitas del abuelo". Este tuit refuerza la idea de permanencia de las declaraciones de Casado, pero al mismo tiempo refuerza también eso que hemos llamado meta hipótesis, en el sentido que toda la postura del $\mathrm{PP}$, independientemente de quien realice las declaraciones, o en qué tiempo se hagan, va en la misma línea. Por lo que sea, a ese partido (lo vimos también con Aznar en Irak) le cuesta rectificar.

Aludir a los muertos europeos en la II Guerra Mundial es sin duda una falacia. Santamaría y Casals (2000:170) definen este rasgo retórico como "un argumento que no siendo válido se presenta -consciente o inconscientemente- como tal por lo que puede llevar a engaño a una persona poco alerta". Y, ciertamente, esa definición se 
ajusta como anillo al dedo a las palabras de Hernando. Y no solo a ellas, sino también a ese aire de superioridad y seguridad que, gestualmente y por medio del tono de voz, desprende al realizarlas. Cualquier telespectador "poco alerta" da por buena esa premisa porque el énfasis no se pone ahí, que es un hecho que se da por cierto, sino en lo que viene después, en "imagínese usted". La audiencia recrea en su mente una Europa con la tierra removida buscando cien millones de muertos.

Alejando un poco el foco, operación que en política nunca está de más, se puede apreciar en las declaraciones del portavoz popular un ejercicio de desinformación. En alguna de sus acepciones, Álvarez y Secanella (1991:365-375) definen este concepto con las siguientes palabras: "La desinformación estratégica ayuda a la ejecución de las tareas del Estado y se dirige a despistar al enemigo en lo concerniente a las cuestiones básicas de política de Estado". No es aventurado suponer, aunque es indemostrable, que las polémicas que inicia y/o alimenta Hernando esconden la intención de tapar otros escándalos de su partido, sobre todo de corrupción, en una época en que esta lacra ha salpicado con especial virulencia al PP. Como decíamos es indemostrable este argumento, a no ser que contáramos con algún documento filtrado que lo acreditara pero, como decíamos, no es aventurado. En cualquier caso, la desinformación tiene también otras acepciones, como "información falsa, incompleta o sesgada, que es pasada, alimentada o confirmada hacia un grupo, un individuo o un país" (Ibid.). Aquí nos podemos encontrar algo que encaja más con las palabras de Hernando. Si bien antes las hemos tildado de falacia bajo la órbita del periodismo de opinión, pueden admitir también su inclusión en el periodismo informativo, y dentro de él en este concepto de desinformación. Pedir que alguien se imagine el caos que sería para Europa tener que desenterrar cien millones de muertos, obviamente no es una información, pero, en cierta forma, al equipararse con la situación española, se está diciendo que esos muertos de Europa están enterrados en cunetas y en fosas comunes, y que cualquier reivindicación de reabrir esas fosas sería inmediatamente rechazada. Eso sí puede entrar dentro del terreno de la desinformación por cuanto supone una premisa, no un juicio, que no se corresponde con la realidad, y puede albergar "información falsa, incompleta o sesgada". 
Las declaraciones de Hernando, como no podía ser de otra forma, produjeron rechazo en la red desde los primeros días: El 25 de noviembre una usuaria decía: "Rafael Hernando cada día que pasa da más vergüenza". El 17 de junio de 2015, Twitter se hacía eco de un artículo de Infolibre, cuyo titular decía: "Víctimas del franquismo piden por carta a Rafael Hernando que deje su escaño por humillarlas”. A pesar de que habían pasado casi dos años, la herida seguía abierta y la Asociación para la Recuperación de la Memoria Histórica (ARMH) fue entonces cuando decidió efectuar esa petición. Curiosamente, en otro caso de paralelismo entre los dos políticos populares analizados, Hernando afirma también en este artículo que sus declaraciones nada tienen que ver con las de Guillermo Zapata y vuelve a insistir en que las suyas se tergiversaron.

El rechazo general que produce Hernando es tal que hay usuarios que manifiestan su intención de no volver a ver un determinado programa de televisión por habérselo encontrado en él. El 29 ago. 2015, uno decía: “@extaNocheTV creo que para bajar el share del programa habéis elegido bien el sujeto \#Rafael Hernando. Todo para vosotros hasta la próxima". Ese mismo año, el 22 de diciembre, otro afirmaba sobre la presencia del político en el programa televisivo "Al Rojo Vivo": “ \#Rafael Hernando en \#arv me ha dado un retortijón. Se piensa que todo el mundo tiene el mismo coeficiente intelectual q el (-2\%)." También relacionado con la televisión, aunque esta vez en tono paródico, una imagen que ilustra perfectamente lo que siempre se espera de Hernando (también de Casado, aunque en menor medida) es el tono faltón, el exabrupto, el insulto. El partido, además, les ha asignado los máximos puestos de política comunicativa: Hernando pasa en diciembre de 2014 de portavoz adjunto en el Congreso a portavoz, y Casado - recordemos- era vicesecretario de comunicación en 2008, cuando efectuó sus polémicas declaraciones, y en enero de 2015 es nombrado portavoz electoral del PP para las elecciones municipales y autonómicas de mayo de ese año. El partido no solo no mitiga el tono beligerante de ambos políticos, sino que les jalea, les premia con ascensos, algo que, por otra parte, también lo ponía de manifiesto un twittero. Su electorado no quiere un partido dialogante y conciliador. La imagen televisiva paródica a la que nos referíamos volviendo a los mensajes de la red- es la de un Hernando caracterizado de Homer 
Simpson encabezando un tuit que dice, el 2 de febrero de 2016: "Seguro que \#Rafael Hernando\#pp dice algo gracioso..."

Durante ese final de 2016 y principios de 2017 nos lo seguimos encontrando en Twitter (en "Destacados" y en "Recientes", sin que haya nada en "Vídeos", en "Noticias" o en "Transmisiones") atacando tanto al PSOE como a Podemos, insultando y siendo respondido: "\#Rafael Hernando Hipócrita! si montas polémicas con tal de salir en los medios de comunicación! ¡La primera hiena eres tú!”;“\#rafael hernando Ese señor franquista, para que la culpa es siempre de los demás nos lo encontramos dando siempre clases de democracia". Incluso lo hallamos también tomando parte activa en procesos de corrupción. En noviembre de 2016, un mensaje en la red dice: "Gürtel. isabel jordán asegura que contactó con el pp a través de \#rafael hernando, actual \#portavoz en el .." Sus ataques no se limitan a otros partidos políticos, también tienen como objetivo los jueces: "\#Rafael Hernando declara que hay jueces que se inventan delitos que no figuran en el \#Código Penal. Esto sres.es DE JUZGADO DE GUARDIA!!!!.” Naturalmente, los insultos prosiguen: “\#Rafael Hernando; A este pelele no hay que tomarlo en serio, iba para payaso pero eligió la política porque para él es lo mismo". Una foto que ilustra perfectamente una de sus muecas características va acompañado con el pie: "Cara vómito".

En marzo de este mismo año van a verse justificados los insultos que acabamos de ver, pues se va a volver a poner de manifiesto el carácter absolutamente despreciativo de Hernando. El día 7 Público informa de que "La ARMH lleva a Hernando ante la Fiscalía por su burla a las víctimas del franquismo". El diputado popular había declarado, en referencia a las víctimas del franquismo, que "estar todos los días con los muertos para arriba y para abajo" es el "entretenimiento de algunos". Es la segunda vez, recordemos, que esta asociación denuncia Hernando. La fiscalía, sin embargo, no vería delito en esas palabras. El político, claro, no se quejó entonces de la decisión de la justicia.

Estas segundas declaraciones de Hernando entran también de lleno en el concepto de manipulación que estudiábamos para Casado. Veamos: Decir "estar todos los días con los muertos para arriba y para abajo" da a entender que quienes eso hacen, una vez conseguidos sus objetivos de dar una sepultura digna a sus familiares, 
quieren más, y continúan con peticiones de nuevas reaperturas de sepulturas. Pero se oculta (manipulación) que quien eso hace lo hace precisamente porque sus reivindicaciones no han sido atendidas, y sus familiares siguen sin ser enterrados dignamente. Eso por no entrar en la palabra "entretenimiento" que hace suponer que los descendientes de las víctimas del franquismo son gente ociosa que no tiene otra cosa que hacer que buscar tumbas por diversión. Es la misma técnica manipulativa de antes. Cuando lo de las "subvenciones", Hernando quiso dar a entender que a los familiares de las víctimas solo les movían en su búsqueda inconfesables motivos económicos.

Desde un punto de vista del discurso periodístico y de las normas éticas que rigen cada una de sus fases, es muy habitual oír a diario a políticos, a gente que a menudo se la relaciona con la actualidad, a tertulianos, e incluso a periodistas decir "esa es su opinión" o "es mi opinión", queriendo decir con ello que bajo esa premisa pueden decir lo que quieran. Pero eso solo se puede defender desde la más absoluta ignorancia del concepto de opinión y de su diferencia con interpretación y con información. Viene esto a cuento de que, aun sin haber salido expresamente en los textos reproducidos en esta comunicación esa excusa, es normal que se invoque, y flota en el ambiente la creencia de que un político, por el hecho de invocar esa supuesta "libertad de opinión", puede decir el primer despropósito que le venga a la cabeza. Ya Lester Markel, en los años cincuenta del siglo pasado (vid. Martínez Albertos 1991:214) establecía nítidamente la diferencia entre los tres conceptos. La opinión requiere un juicio de valor, la interpretación un juicio de hecho basado en razones probatorias objetivas, y la información un relato de los hechos sin ningún tipo de juicio. Esta diferenciación ha sido mantenida en nuestro país por los más diversos autores como el propio Martínez Albertos (Ibid.), Grijelmo (2008) y Paniagua (2017). Decir que "estar todos los días con los muertos para arriba y para abajo parece ser el entretenimiento de algunos" no es una opinión. Lo sería decir por ejemplo "cualquier reivindicación sobre la reapertura de tumbas debe ser inmediatamente rechazada". Pero, claro, ¿qué ocurre? Que ese tipo de enunciados no son políticamente correctos (aparte de ser -en el caso de este ejemplo, en concreto- ilegales). Por eso se enmascaran bajo la apariencia de interpretación. "Parece ser el entrenamiento de 
algunos" sería una interpretación legítima (incluye un juicio de hecho) si se basara en razones probatorias objetivas, cosa que no ocurre en absoluto. No vemos que los buscadores de tumbas de sus antepasados lo hagan por "entretenimiento", utilizando esa palabra según el estándar común de la lengua.

Lo mismo, exactamente, se puede decir de las primeras declaraciones a propósito de "Algunos se han acordado de su padre, parece ser, cuando había subvenciones para encontrarlo". Ese "parece ser" supone, otra vez, una interpretación ilegítima por cuanto no es manifestación de una evidencia. Pero tampoco es una opinión porque no introduce en la frase ningún juicio de valor. Escudarse, por tanto, en que la opinión es libre es una burda maniobra que bajo ningún concepto, y al margen de la bajeza moral de tales afirmaciones, puede esgrimirse cuando lo que se está expresando es claramente algo que no entra dentro del campo discursivo de la opinión.

\section{Conclusiones}

1.- Las declaraciones de Casado y Hernando se enmarcan dentro de una línea comunicativa del Partido Popular que consiste en despreciar a las víctimas del franquismo en un intento de negar o atenuar los crímenes cometidos por dicho régimen.

2.- Esa línea comunicativa busca ridiculizar a otras posturas políticas, tradicionalmente consideradas de izquierdas, y a cualquier asociación que intente luchar por la dignidad de las víctimas porque eso le da al PP réditos electorales.

3.- Twitter, en una abrumadora mayoría, que supera el $90 \%$ de los usuarios, se manifiesta en contra de las declaraciones de ambos políticos, unas veces mediante el insulto directo y otras rebatiendo seriamente sus tesis.

4.- El Partido Popular no intenta mitigar la forma de herir la memoria que suponen las declaraciones de Casado y Hernando. Por el contrario, premia a esos políticos con ascensos porque el propio ascenso es una forma más de comunicación del partido. 
5.- Desde el punto de vista de la retórica argumentativa, y de la sustentación de la interpretación e información periodísticas, estas declaraciones no constituyen opinión y sí interpretación ilegítima pues está basada en falacias, manipulaciones y premisas falsas. 


\section{Bibliografía}

AGUILAR, Paloma (2006). Presencia y ausencia de la guerra civil y del franquismo en la democracia española. Reflexiones en torno a la articulación y ruptura del pacto de silencio. En Aróstegui, J. y Godicheau, F. (eds.) Guerra Civil. Mito y memoria. Madrid: Marcial Pons.

ÁLVAREZ, Jesús Timoteo y SECANELLA, Petra María (1991): "Desinformación" en Diccionario de ciencias y técnicas de la comunicación, Madrid, Ediciones Paulinas.

ARÓSTEGUI, Julio (2006). Traumas colectivos y memorias generacionales: el caso de la guerra civil. En Aróstegui, J. y Godicheau, F. (eds.) Guerra Civil. Mito y memoria. Madrid: Marcial Pons.

BURGUEÑO, José Manuel (2008): La invención en el periodismo informativo, Barcelona UOC.

EIROA, Matilde (2014): "La guerra civil española en la actualidad cibermediatica" en

Studia Historica. Historia Contemporánea, vol. 32, pp. 357-369.

GRIJELMO, Álex (2008): El estilo del periodista, Madrid, Taurus.

HESÍODO (2010): Teogonía. Trabajos y días. Escudo. Certamen, Madrid, Gredos.

MARTÍNEZ ALBERTOS, José Luis (1991): Curso General de Redacción Periodística (Ed. Revisada), Madrid, Paraninfo.

NAVARRO, Vincenc. (2002). Bienestar insuficiente, democracia incompleta. Barcelona: Anagrama.

NÚÑEZ, Mirta (2004). Los años del terror. La estrategia de dominio y represión del general Franco. Madrid: La esfera de los libros.

PANIAGUA, Pedro (2017): "El reportaje" en PARRAT, Sonia, Manual práctico de Redacción periodística, Madrid, Síntesis. 
PONS, Anaclet (2013). El desorden digital. Guía para historiadores y humanistas. Madrid: Siglo XXI.

REIG, Alberto (2009). Cultura política y vía pacífica a la democracia. En Olmos, I. y Keilholz-Rühle, N. La cultura de la memoria. La memoria histórica en España y Alemania. Madrid: Iberoamericana.

RIHAWI, Natalia. (2017). El papel de la redes sociales en la cibercultura: El caso de la "Primavera árabe". Tesis doctoral, UCM, Madrid: Inédita.

SANMARTí, Josep María; PANIAGUA, Pedro; y de RAMÓN, Manuel (2002): "Periodismo, la plebeyización triunfante. Los medios como indicadores de la Historia", Actas del III Simposio de Historia Actual, pp. 437-445, Logroño, Instituto de Estudios Riojanos (IER).

SANTAMARÍA, Luisa y CASALS, María Jesús (2000): La opinión periodística. Argumentos y géneros para la persuasión, Madrid, Fragua.

SMALL, Tamara A. (2011). "What the hashtag? A content analysis of Canadian politics on Twitter", en Information Communication \& Society, vol. 14, n 6, pp. 872-895. Citado por Franch, P. y Yeste, E. (2015). "Las redes sociales como herramienta de recuperación de la memoria colectiva. Contenido político de la cuenta en Twitter de John F. Kennedy", en Zer, vol. 20, núm. 39, pp. 127-144.

\section{6.- REFERENCIAS HEMEROGRÁFICAS Y ENLACES}

.- El Periódico, 19.6.2015

http://www.elperiodico.com/es/noticias/politica/pablo-casado-carcas-fosasguerra-abuelo-comunicacion-cambios-partido-popular-4288555

.- eldiario.es, 14.1.2015

http://www.eldiario.es/rastreador/Pablo-Casado-izquierdas-guerraabuelo 6 345825420.html 
PEDRO PANIAGUA

Una forma calculada de herir la memoria histórica. Repercusión en Twitter de las declaraciones de los diputados del Partido Popular Pablo Casado y Rafael Hernando

-- El Periódico, 26.11.2013

http://www.elperiodico.com/es/noticias/politica/rafael-hernando-victimas-delfranquismo-solo-acuerdan-sus-padres-cuando-hay-subvenciones-2872234

.- Público, 7.3.2017

http://www.publico.es/politica/armh-Ileva-hernando-fiscalia-burla.html 